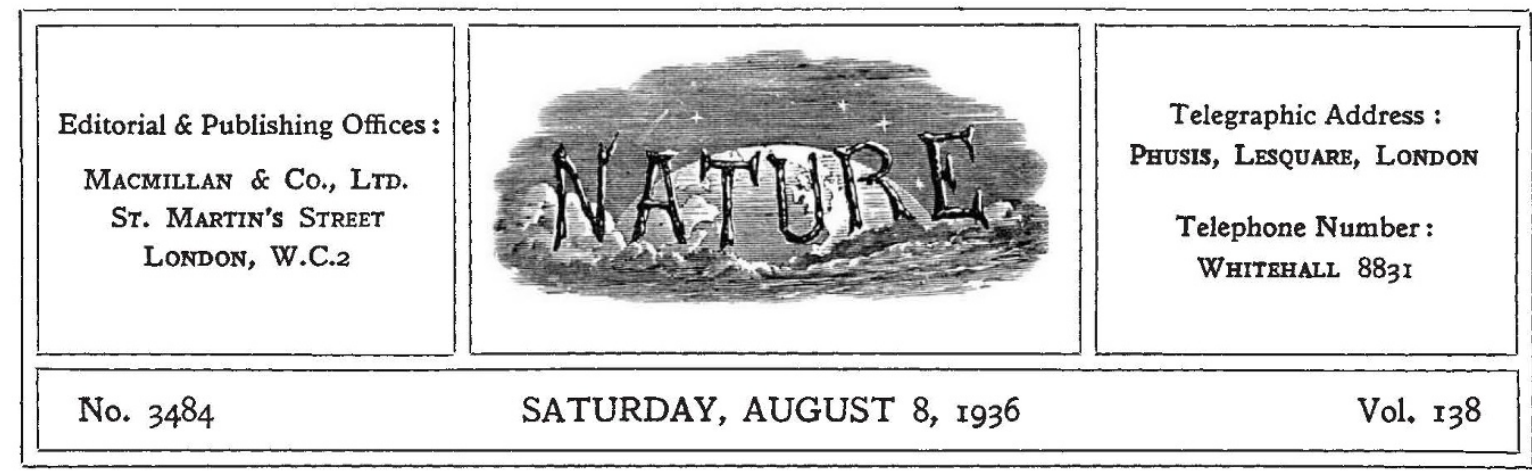

\title{
Purposes of University Education
}

$I^{N}$ the plea for devising an education which would secure for us representatives capable of co-operating intelligently with technical experts in constructive social enterprise and would also teach us how to choose them, which formed one theme of his Conway Memorial Lecture (see Nature of July 25, p. 139), Prof. L. Hogben uttered a warning against the teaching of science for vocational purposes which deserves close attention. He raises essentially the same question regarding all education that was raised of university education by the recent report of the University Grants Committee (see NATURE of June 27, p. 1057), and the wider question should in fact be faced before we really formulate our answer to the question, what is the purpose of university education.

The valuable study of education for citizenship in secondary schools, issued early this year under the auspices of the Association for Education in Citizenship (London: Oxford University Press. 5s. to non-members ; $3 s .6 d$. to members), directed attention to the inadequacy of indirect education for citizenship to-day. Experience has shown that a man with a good general education based on languages or science may be an excellent father, an excellent business or professional man and at the same time a bad citizen. The political world has become so complex and difficult that it is essential to train men just as consciously and deliberately for their duties as citizens as for their vocation or profession.

The monograph to which we have just referred proceeds to discuss how the direct teaching of citizenship may be achieved, particularly by linking it to the subjects at present taught in secondary schools. Prof. Doris L. Mackinnon, for example, suggests that it is a prime duty of the teacher of science to let the pupil understand from the beginning what are the responsibilities in common life which the scientific discipline lays on all those who have once submitted to it. Moreover, the suggestions in regard to the teaching of clear and of accurate thinking made by Prof. G. C. Field and Dr. R. H. Thouless are scarcely needed more in any section of the community than in regard to the training of the scientific worker.

The present unsatisfactory position arises in fact from the growing tendency towards vocational education, and perhaps more particularly the teaching of science for vocational purposes. Already this has invaded the public and other secondary schools and spread far beyond the universities and technical colleges. In a highly organized society political administration must be the vocation of certain people. It is also true that intelligent citizenship is no longer possible without some understanding of the place of science in the everyday life of the whole nation; and the teaching of science needs to be adapted to such requirements rather than to those of assisting the few to gain a livelihood in a particular way.

If, therefore, we could re-orientate the teaching of science in both post-primary and secondary schools so that it would be taught as part of the equipment of everyone for living in a scientific age, and not as the first stage in preparation for a career in science, we should have taken one step to facilitate co-operation between the technical expert and the political administrator. If, further, by means of training for citizenship on the lines advocated by the Association for Education in Citizenship, we could ensure that those entering a university had received at any rate some equipment in this respect before embarking on their specialized studies, we should be in a much 
sounder position to discuss the question of the quality and quantity of university education.

As the report of the University Grants Committee points out, the engineer, chemist, medical man or schoolmaster trained at a university is rightly expected to have received a sound technical training in the particular calling or subject he has studied. Whether he has also received that stimulation and enrichment of the whole mind which enable him to lead a fuller and more interesting human life, and to play more adequately his part as member or leader of the community, must depend at least partly on the way in which he has been prepared for the training he receives at the university.

If the tendency to specialize at a too early age, and particularly in the later years of school life, has had insidious consequences and needs to be resisted strenuously, at least it should teach us that there can be no hard and fast separation between secondary education and university education. One must be planned in relation to the other, and we cannot throw on the university stage the whole responsibility of training a man not only as a skilled worker but also as a member of society and a human being.

The special responsibilities of the universities in this field must of course be recognized. Industrial and commercial appointments are being thrown open to university graduates over an increasingly wide field. The growing extent to which leadership in commerce and industry, like that in national and local administration, is passing under the influence of professional men, means that the great majority of those who become leaders in the national life will continue to be drawn from those who have received a university training. No university can fail to recognize the opportunities of service in ensuring conditions of training which enable its students to go into the world with minds richly informed, unsleeping in the exercise of a critical intelligence and imaginatively alive to the human issues underlying the decisions they may be called upon to take.

The importance of giving due attention to these fundamental issues at the present time can scarcely be over-emphasized. Mechanization of thought is a peril in Great Britain as in other countries, and the suppression in the universities of several European and other countries of all independent thought and critical discussion of the principles of government, or of the meaning of life, throws a special responsibility upon British universities if the Greek tradition of candid and intrepid thinking about the fundamental issues of life is to be preserved for mankind.

Training for citizenship is a part of this wider question of training for life, but the two can scarcely be separated in any discussion of education to-day. Both the school and the university, each within its own limits, must endeavour to give its students a training for life, and this is even more important than training for a particular vocation or career. It is at last becoming more widely recognized that it is scarcely possible for a university to equip its studen is with the technical knowledge which might be expected to be of immediate use to them in any branch of industry they may enter on leaving the university. The detail of technical work can in fact be mastered only by practical experience after the student has left the university. The function of the universities in training scientific workers and technical men for industry is rather to give them such a knowledge of the principles of science and technology that they are able to bring trained minds to bear upon the understanding of practical problems which they encounter in their industrial or professional life.

The stimulation of thought, the widening of its horizons, the development of the faculty of judgment, and the evoking in its students of the energy of the soul in which Aristotle found the essence of true well-being, are the essential contributions to education which characterize the university rather than the schools. The dissatisfaction with many graduates of universities to-day is largely due to the fact that their primarily specialized training has robbed them of the essence of a university education and left them unequal to the demands which the major problems of life and industry make upon them when questions of value and judgment are involved. Moreover, specialization in itself is not so much criticized as premature specialization and the inadequate foundation upon which it is built, with the result that many of those completing long courses of study at a university in medicine or science, for example, are in danger of being uneducated persons.

Prof. Hogben showed convincingly in his lecture how ability to sort out the real issues, and to think clearly on the values as well as on the scientific and technical factors involved, are demanded to. day in our political leaders and in some degree in those who elect them. The professional aspects of after-life are to-day scarcely the major preoccupation of the universities, at least so far as they are 
not linked up with the wider question of training in thought which they give to their students and of the linking of thought to action.

It is no part of the duty of a university to inculcate any particular philosophy of life. Never, however, was it more important than it is today that it should stimulate and train its graduates to think strenuously about the great issues of right and wrong, of liberty and government on which for the individual and for the community a balanced judgment is essential to a rational life. Without overlooking the place of research in the functions of a university or the desirability of upholding the value of learning for the sake of learning, the linking of knowledge to action is of such supreme importance at the present time that even the research activity of the universities needs to be re-orientated so as to secure that the advance of knowledge proceeds on a more even front. Only when our research effort is directed in some relation to the fundamental needs of society can we hope to redress some of the evils which the rapid advance in the physical sciences as compared with the biological or social has brought in its train.

An undoubted consequence of the redistribution of our comparative research effort between the physical and the biological and social sciences in the way urged by Dr. Julian Huxley or Prof. W. McDougall, for example, would be not merely the fertilization of thought in the social sciences and the breakdown of barriers between them but also the stimulation of thought generally in these fields. As in the physical sciences, we might witness significant advances through the overlapping of traditional disciplines in several branches of knowledge.

Given this redirection of research effort and the stimulation of thought in social and biological problems, the training of men and women who will bring unprejudiced minds, critical powers and moral courage to bear upon the new and difficult problems which they must meet in this era of physical science should become much simpler. To some extent, the absorption of the graduate into industrial or other employment may become a simpler problem because he will be better fitted to take any place as an intelligent member of the community, though the warning of the University Grants Committee in regard to the limitation of the members of those entering a university needs to be kept in mind. Nor can we overlook the importance of that early training for citizenship which those entering a university should share with those whose school education finishes at the post-primary or secondary school education stage. There at least must be laid a foundation from which a university can fittingly start to impart, not a mere training for livelihood, but a training for life and for leadership, so that its graduates are distinguished by a sense of values, a wide vision and a capacity for the creative thought and judgment which require only the ripening of experience to enable them to bring a trained mind to bear on any of the problems with which they may afterwards be confronted in their professional, industrial or civic life.

\section{Morphology of Muscles}

The Cranial Muscles of Vertebrates

By Prof. F. H. Edgeworth. Pp. ix +493 . (Cambridge : At the University Press, 1935.) $£ 55 s .0 d$. net.

$\mathrm{I}^{\mathrm{N}}$ this large, copiously illustrated and splendidly produced volume, Prof. Edgeworth has brought together the knowledge which has been gained in the last hundred and fifty years of the comparative anatomy and embryology of the cranial muscles (and their motor nerves) in vertebrates. The author is well equipped for this task. Though not a professional zoologist-he was for many years, until recently, professor of medicine in the University of Bristol-he has long been a worker on this subject "so far as medical practice and teaching permitted", and has become widely known from his many published observations which have added to our knowledge of the subject.

This memoir is a notable and important contribution to vertebrate morphology, and contains the most complete account which has been published of the homologies of the cranial muscles. Its scope may be indicated by mention of the principal subjects discussed in its chapters. They begin with a discussion of the embryonic head mesoderm and its segmentation, of the relation of the muscle plates of the head to the myotomes of the body, and of the number of the branchial segments. The 
author finds that in the cephalic mesoderm, premandibular, mandibular and hyoid segments are followed by a "branchial region" in which the number of segments varies in different phyla, and, as he has found, among the genera of any one phylum. He puts forward the view that this variability occurs not by the intercalation or dropping out of segments but by "the separation of the branchial region as a whole into a greater or a lesser number of segments than is usual in their respective phyla".

The chapters which follow show the extensive range of the author's observations on the development and anatomy of the cranial muscles in the vertebrates from the Dipnoi to mammals. The subjects dealt with include the external ocular muscles, the palato-quadrate bar in Ichthyopsida and Amphibia, the mandibular muscles and the palato-quadrate bar in Sauropsida, and the palato-quadrate and mandibular muscles in mammals.

Separate chapters deal with the hypobranchial skeleton and the hyoid muscles, the superficial facial and cervical muscles of mammals, and the branchial muscles. Considerable space is devoted to the description of the Cucullaris muscle, and the author presents a condensed but valuable account of this muscle throughout the vertebrates. The first stage in its phylogenetic history is represented in the Dipnoi, in which a muscle, the "constrictor branchialis V", extends back as a broad sheet, "whose ventral edge is attached to the pectoral girdle and coraco-branchialis V. Probably generally in Holocephali and Selachians it is developed from the dorsal ends of all five branchial muscle plates. These extend forwards and backwards and fuse together to form a longitudinal muscle, the anterior end of which becomes attached to the cranium and its posterior end to the shoulder girdle. It is innervated by a branch of the ' $R$. intestinalis $\mathrm{X}$ ', the fibres of which can be traced from the caudal, exclusively motor, fibres of the vagus or vago-accessorius.

"A cucullaris is present in most of the Amphibia and in the Reptilia. In birds there is no cucullaris -its function is taken over by the cranio-cervicalis, which also extends from the head to the shoulder girdle, but is innervated by a different nerve, the $\mathrm{N}$, hypoglosso-accessorius. In mammals a cucullaris is present, developed from the most caudal branchial plate, and extends back to the limb as a single band."

The number and complexity of the cranial muscles is illustrated by the fact that thirty-eight pages are required merely for a list of the synonyms used by different writers for individual muscles, a list which the author states is "far from complete". This section is notable, not only from the wide range of vertebrate forms, but also from the number of embryos at different stages of development which he has examined. Its value is enhanced by the number of illustrations given in corroboration of the facts stated in the text.

The author discusses at length some of the difficulties which arise in determining muscle homologies. The segment of origin of homologous muscles is in general constant from genus to genus and from phylum to phylum, but exceptions occur. Anatomists have long been accustomed to consider that the nerve supply to a muscle affords sound and reliable evidence of its homology, and this is generally the case, but again exceptions occur; the muscle plate of the mandibular segment is as a rule innervated by the fifth nerve, but in certain instances the seventh nerve may be the source of nerve supply, and this arises, according to the author, from the shortness of the first gill cleft.

The author has dealt more fully than is usual with the relation of nerve to muscle and not only with the peripheral pathway through which muscles are innervated, but also with the significance and the homologies of the groups of motor cells, spinal and medullary, from which the nerves are derived. Experimental evidence is made use of whenever possible to determine afferent from efferent fibres in different nerves, and a chapter is devoted to analysis of the groups of efferent cells in the "occipito-spinal motor cell column".

The aim of the author has been to ascertain what evidence the study of these muscles gives on the problem of the genetic relation of the vertebrate phyla "and so of the phylogenetic history of Man in the remote past". It may perhaps be doubted whether the material which he uses is capable of affording such information. The successive changes undergone by the developing embryo and its parts give only a general indication of phylogenetic history. The skeleton, the central nervous system and many of the viscera have been studied from this point of view, but have yielded no information of great significance on this problem. Where these systems have failed, it is scarcely to be expected that the study of muscles would be more fruitful, but the author's studies have led him to certain conclusions as to what were the characters of the ancestral forms from which the existing vertebrate phyla have originated, and these are given in detail in the final chapter.

No one who works, as the author has done, on broad problems of morphology can fail to have his interest excited in the significance of the whole embryological process and the variations in its details which occur in different forms. The author's 
attitude towards this problem is best expressed by some sentences which may be quoted:

"The development of the cranial muscles gives much evidence of its purposeful character."

"In some unknown way the growing organism appears to foresee future needs, and sets to work with such material as it has to develop the necessary structures along the lines followed by its ancestors".

"Experimental embryology shows that the growing organism from the zygote upwards is a whole and not merely an aggregate of parts. Similarly, animals are psychological units, characterised by memory and purpose, by striving after ends in view. The variations in the development of homologous structures and in the structures by which the same functions are carried out show that this psychological factor is of great importance from the first."
"This immaterial, non-spatial, teleological factor, the mind, can initiate and inhibit physico-chemical processes. Life, development of individual organisms and evolution are primarily due to this power."

In view of the size and form of this volume and the wealth of illustrations-there are 841 figures, clearly drawn and reproduced on special paper, pp. 301-493-the price cannot be considered unduly high, though it may restrict its circulation. It is indispensable to workers in vertebrate morphology, and the author deserves the highest commendation for the care, the skill and the wide range of his inquiries, and is to be congratulated on the completion of a work which is a credit to British zoology.

David Waterston.

\section{A Study of the Ephemeroptera}

The Biology of Mayflies:

with a Systematic Account of North American Species. By Prof. James G. Needham, Dr. Jay R. Traver, Prof. Yin-Chi Hsu, assisted by Specialists in certain Subjects. Pp. xvi +759 . (Ithaca, N.Y. : Comstock Publishing Co., Inc., 1935.) 7.50 dollars.

PROF. JAMES G. NEEDHAM, of Cornell 1 University, the senior author of this book, has made a very valuable contribution to the knowledge of a little-known order, the Ephemeroptera. This biology has one outstanding feature of merit, it is original work. Prof. Needham has gathered around him a band of enthusiastic workers who have come forward and in their own words and under their own names, have told us of the results of their researches. Two of these workers appear with Prof. Needham as joint authors. The second author, Dr. J. R. Traver, has been responsible for nearly the whole of Part 2 , the systematic description of the North American species, about five hundred pages, as well as a portion of Part I dealing with life-history and collecting. The third author, Prof. Yin-Chi Hsu, is responsible mainly for the chapters dealing with structure and anatomy. There are further chapters on anatomy under the pen of Dr. V. Knox.

This book is perhaps the most comprehensive that has ever been undertaken on the biology of the order. Pictet, in 1843, dealt with both anatomy and systematics in his "Histoire des Névroptères"; Eaton's classic monograph on "Recent Ephemeridæ" was mainly systematic; there have been sundry papers written by various authors since 1888, the date of Eaton's great work, scattered through entomological literature.
Prof. Needham's book will appeal, of course, mainly to the specialist, having regard to the fact that so large a proportion of its space is devoted to American systematic work; but the biology proper, consisting as it does of no less than 236 pages, has an interest not only for entomological workers but is also of economic value to all who are concerned with the study of the food of fishes, in Great Britain, more particularly the trout.

Chapter $i$ deals with the life and habits of the Ephemeroptera or, as they are perhaps unfortunately called in America, the mayflies. It is unfortunate because the title is misleading. Not only do these insects appear on the wing during every month of the year-at least they do so in Great Britain-but also the name mayfly in the fly-fisher's world is restricted in its application to species of Ephemera, and the fly-fisher's popular nomenclature may be traced back for nearly five hundred years.

While, generally speaking, the life of an ephemeropteron is not quite so ephemeral as the name would suggest, Prof. Needham tells us of a species, Callibotis fluctuans, the entire life of which in the winged condition is restricted to some forty-eight hours, during which it emerges from the water, changes from the subimago to the imago stage, pairs, oviposits and finally dies. The mayfly proper, the British species, Ephemera vulgata, on the other hand, has been observed by the writer, at least two months after emergence, having been so long on the wing as to have darkened to nearly black.

America is a country of extremes, and this trite saying applies even to the Ephemeroptera, for we read here that instances have been recorded of 